\title{
ACCESO A LA JUSTICIA DE LA POBLACIÓN MENESTEROSA EN CHILE. PROBLEMAS DE CONSTITUCIONALIDAD DE LOS MEDIOS ARBITRADOS POR EL LEGISLADOR PARA EL EFECTIVO CUMPLIMIENTO DE ESTA GARANTÍA
}

Daniela D. Rosenberg González*

RESUMEN: El sistema de acceso a la justicia en Chile conformado por varias instituciones, presenta graves falencias en lo que respecta a la debida asistencia letrada de personas menesterosas. La Constitución chilena ordena al legislador que proporcione los medios necesarios para que la garantía se haga efectiva. Algunos de estos medios adolecen de problemas fácticos y de constitucionalidad, lo que ha decantado en un ineficiente e ineficaz acceso a la justicia y en el incumplimiento de obligaciones de carácter internacional contraídas por el Estado chileno.

PALABRAS CLAVE: Acceso a la justicia - problemas constitucionales - población menesterosa Abogados de turno.

ABSTRACT: The system of access to justice in Chile, consisting of many institutions, presents serious failures regarding the due professional assistance of needy people. The Chilean Constitution orders the legislature to provide the means necessary for this guarantee to be made effective. Some of these means suffer from factual and constitutional problems, which have ended in an inefficient and ineffective access to justice and in the breach of international obligations contracted by the Chilean State.

KEY WORDS: Access to the justice - constitutional problems - needy population - court appointed attorney.

\section{Introducción}

Este trabajo persigue revisar críticamente y desde una perspectiva dogmáticaconstitucional, los medios generados por el legislador para garantizar el acceso a la justicia de la población chilena que carece de medios propios para procurarse una debida asistencia letrada. Esta revisión pretende constatar que el sistema de acceso a la justicia existente en nuestro país es deficiente y que el trabajo realizado por el legislador para dar efectivo cumplimiento a esta garantía, ha desembocado en una serie de problemas de

\footnotetext{
* Estudiante de tercer año, Escuela de Derecho, Universidad Austral de Chile.
} 
constitucionalidad relacionados con el incumplimiento de la normativa internacional a la cual se ha obligado el Estado chileno.

Comenzaremos explorando brevemente uno de los principales aportes en materia de acceso a la justicia, aquél realizado por Mauro Cappelletti y Bryant Garth ${ }^{1}$, que nos proporcionará una base para adentrarnos en el contenido de la garantía en cuestión y los principales problemas que la afectan ${ }^{2}$.

A posteriori, revisaremos la consagración de este derecho fundamental en la Constitución Política de la República de Chile de 1980 (en adelante CPR), y los principales medios que el legislador ha generado para la materialización de la garantía de acceso a la justicia, centrando el análisis en dos instituciones: Corporación de Asistencia Judicial y Abogados de Turno. Subsiguientemente, examinaremos los principales problemas fácticos y constitucionales asociados a ellas.

Finalmente, una revisión de la normativa internacional de Derechos Humanos a la que se encuentra obligado el Estado de Chile, nos mostrará la discordancia existente entre ésta y el verdadero potencial de eficacia de las normas chilenas sobre acceso a la justicia de la población menesterosa. Con ello constataremos que de facto se está produciendo un incumplimiento de normas internacionales, producto de que el sistema de acceso a la justicia creado en Chile (para la población carente de recursos), presenta la siguiente dificultad: los medios empleados para ello, se han estructurado y funcionan de manera tan deficitaria, que terminan conculcando el derecho que debieran garantizar, razón por la cual resulta urgente reformarlos.

2. Un acercamiento a la idea de acceso a la justicia

Los derechos fundamentales, desde su aparición histórica como protagonistas de la necesidad de limitación al poder político, han ido configurándose de distinto modo conforme han sido recogidos y consagrados en las cartas fundamentales de cada país. Es evidente que la ideología y la forma de Estado que se adopte, influyen determinantemente en el contenido y la fuerza garantista con que los derechos humanos son concebidos y materializados en cada sociedad. La CPR de 1980 no ha sido la excepción a la regla, y es la expresión latente del pensamiento político de quienes le dieron vida en determinado momento histórico. Iusnaturalista y de corte liberal (en materia económica), nuestra carta fundamental presenta graves y lamentables carencias en materia de derechos económicos, sociales y culturales, lo cual no ha variado de manera significativa desde la vuelta a la democracia, siendo esta última cuestión aún más grave si consideramos que las condiciones están dadas para propulsar reformas y mejoras eficaces desde hace varios años.

\footnotetext{
${ }^{1}$ Para una revisión exhaustiva de los principales problemas de acceso a la justicia subyacentes en la mayoría de los sistemas jurídicos, ver estudio comparativo en texto completo: CAPELLETTI, Mauro y GARTH, Bryant. El acceso a la justicia, La tendencia en el movimiento mundial para hacer efectivos los derechos. México D. F., Fondo de Cultura Económica, 1996.

${ }^{2}$ Cabe señalar que el objeto de este análisis en caso alguno pretende abarcar en forma exhaustiva la problemática del acceso a la justicia por tratarse, en opinión de la autora, de un tema que debe ser enfrentado desde una óptica multidisciplinaria dada su complejidad. En consecuencia, nos centraremos en aquellas aristas del problema que han generado más críticas en nuestro país.
} 
Como una muestra de la configuración semántica de nuestra CPR, encontramos una serie de derechos fundamentales que no son sino meras directrices de contenido tan amplio que terminan siendo, lamentablemente, tristes declaraciones de buena voluntad al no alcanzar un adecuado y cabal desarrollo legislativo. El derecho de acceso a la justicia de la población menesterosa es un claro ejemplo de este deficiente trabajo legislativo, donde el sistema que se ha erigido para materializar esta garantía adolece de falencias tan graves, que no ha hecho sino truncar la finalidad para la cual ha sido destinado. Famélica es la necesidad por reformar este sistema, pues paupérrima es la eficacia práctica de un catálogo de derechos fundamentales, cuando aquel derecho que garantiza la puerta de entrada al debido resguardo, protección y realización de todos los demás, adolece de tal estrechez que hace casi imposible, para un grupo significativo de la población, acceder a ello eficazmente.

Para poder analizar cabalmente la consagración de esta garantía en nuestra CPR, parece necesario adentrarnos previamente en la significación que la idea de acceso a la justicia ha adquirido en estos últimos años, que gracias a los aportes doctrinales de diversos autores ha conseguido ampliar sus horizontes, yendo más allá de lo estrictamente jurídico.

Asumiendo que dar una definición de acceso a la justicia resulta algo complejo, nos arrimaremos a la definición dada por el nacional Nicolás Balmaceda en su trabajo sobre el tema que nos convoca, para quien se trataría de "la posibilidad cierta de que las personas obtengan una solución eficaz a sus necesidades jurídicas y judiciales"3. Si bien esta definición es elocuente respecto del fin del acceso a la justicia, parece incompleta al alero de los aportes hechos en derecho comparado, donde la idea de justicia social está fuertemente ligada a la de igualdad, y a la necesidad de contar con un Estado que participe activamente, generando condiciones y medios eficaces de acceso a la justicia para toda la población y no limite su rol al de mero promotor pues, con ello, se evita que los derechos sean meramente simbólicos y se consigue su real protección al posibilitarse su ejercicio por parte de todos los integrantes de la nación. Entonces, no bastaría con la posibilidad cierta de resolver nuestros problemas de relevancia jurídica, sino que ésta debe ser una posibilidad en igualdad y es el Estado el llamado a asegurarnos que así sea, de manera eficaz y eficiente.

Cappelletti y Garth en su estudio ya referido, plantean un necesario cambio de paradigma en la concepción teórica del acceso a la justicia, donde debiera transitarse desde "un derecho formal del quejoso a litigar o defender una reclamación... hacia un acceso efectivo a la justicia... una completa igualdad de armas"4. Este cambio de concepción teórica debe necesariamente ser llevado a la práctica, toda vez que la sola toma de conciencia al respecto no bastará para mejorar la situación de quienes no pudiendo acceder a la lógica de mercado, deben recurrir a los servicios de asistencia que presta el Estado, para satisfacer su necesidad de defensa jurídica. En su estudio, los autores detectaron situaciones (denominadas barreras) que dificultaban el acceso a la justicia de la población en su conjunto, pero también algunas

\footnotetext{
3 Balmaceda Jimeno, Nicolás. “Corporaciones de Asistencia Judicial y abogados de turno: ¿incumplimiento de una garantía constitucional?” en Revista Chilena de Derecho, Pontificia Universidad Católica de Chile, No 27(4), 2000, pp. 722.

${ }^{4}$ CAPELletTi, Mauro y GARTH, Bryant. op. cit. (n. 1), pp. 11 y 14. Al respecto los autores hacen hincapié en la necesidad de analizar esta garantía atendiendo principalmente a la idea de igualdad entre las partes a la hora de acceder a la justicia, pues consideran que las soluciones y resultados que se obtengan de ello, estarán relacionadas con las cualidades jurídicas de cada parte, y ya no se basarán en ventajas generadas por una desigualdad de armas. Esta situación es el foco de atención de su estudio, junto con el rol que debe asumir el Estado al momento de asegurar la igualdad en el acceso para todas las personas.
} 
situaciones que afectaban específicamente, o en mayor medida, a los grupos de menores recursos económicos. Estas barreras se agruparían en tres categorías: A) El costo del litigio, en que los servicios prestados por abogados resultan demasiado costosos para la población promedio, sobre todo cuando se trata se reclamaciones pequeñas, y a ello se suma, el tiempo que tarda la justicia en generar respuestas para los requirentes (ya sea por complejidad de las causas, por sobrecarga en tribunales, por procedimientos burocráticos, etc.). B) Diferencias entre el poder de los litigantes, ya sean económicas, educacionales, culturales o sociales (pues no sólo los recursos económicos contarían al momento de accionar ante la justicia, también son determinantes factores como el nivel de conocimiento sobre sus derechos y la disposición síquica para recurrir a tales procedimientos, entre otros). C) La frecuencia y el nivel de experiencia que tenga cada persona respecto del sistema judicial (la experiencia genera un mayor o menor grado de familiaridad con los tribunales, lo que ocasiona ventajas comparativas respecto de quien nunca ha enfrentado un tribunal). D) Problemas especiales de los intereses difusos (dificultades de organización, de recaudación de recursos y de armonizar pretensiones cuando el interés a reclamar es de carácter colectivo y el titular del derecho no es una sola persona) $)^{5}$. Resulta interesante destacar que estas barreras están presentes en toda su magnitud en nuestro sistema de acceso a la justicia, y se trataría de dificultades que debemos afrontar todos los nacionales, tengamos o no recursos para procurarnos asistencia y defensa jurídica, ya que hay diferencias que van más allá de la posibilidad de contratar a un abogado. Desde luego, estas barreras se hacen aun más patentes entre aquellos considerados menesterosos, pues su situación es más precaria en términos globales, ya que sin recursos económicos, con carencias socioculturales y educacionales deben, además, afrontar al sistema judicial asistidos por mecanismos defectuosos, e incluso solos, pues el legislador ha estimado que para superar las barreras de la desigualdad, es una medida adecuada hacer facultativa la asistencia letrada.

También es relevante tener presente que estas barreras, tal como lo expresan los autores, están interrelacionadas, por tanto hay que trabajar en todas las áreas involucradas con el acceso a la justicia. Si bien algunos avances ha habido al respecto en nuestro país (iniciativas de información a la comunidad sobre sus derechos, modalidades alternativas de solución de conflictos, entre otras), es necesario que el trabajo sea repartido entre todos los actores sociales, ya que la justicia social es tarea de todos (colectivos, grupos intermedios, clase política, profesionales del área, empresa privada, etc.). No podemos pretender que la carga sea asumida exclusivamente por el Estado, quien debe garantizar adecuadamente y generar mecanismos eficientes y eficaces de acceso a la justicia para la población menesterosa especialmente, más no olvidemos que existen diversos mecanismos para dar solución a este problema, y que no se sustentan necesariamente en la caridad y el paternalismo, tal como lo demuestra el estudio de Cappelletti y Garth, al revisar los distintos sistemas de acceso a la justicia en diversos países ${ }^{6}$.

\footnotetext{
${ }^{5}$ Ibid, pp. 14 y ss.

${ }^{6}$ Ibid, pp. 24 y ss. A modo ejemplar: el sistema Judicare en Inglaterra, donde acreditándose situación financiera y relevancia jurídica de la pretensión, es posible elegir un abogado perteneciente al sistema judicare, cuyos servicios son pagados por el Estado. Otro caso menos paternalista y de carácter mixto, es el de Suecia donde los requirentes pueden optar entre el sistema judicare o un abogado asalariado.
} 


\section{Consagración y materialización del acceso a la justicia en Chile}

El artículo $19 \mathrm{~N}^{\mathrm{o}} 3$ de nuestra CPR, contiene el derecho fundamental de todas las personas a una igual protección de la ley en el ejercicio de sus derechos. Luego, en su inc. $2^{\circ}$ el constituyente asegura que "toda persona tiene derecho a defensa jurídica en la forma que la ley señale y ninguna autoridad o individuo podrá impedir, restringir o perturbar la debida intervención del letrado si hubiere sido requerida". Finalmente se hace cargo del acceso a la justicia de la población menesterosa, estableciendo un mandato al legislador para que procure los medios a través de los cuales este segmento poblacional acceda a asesoramiento y defensa jurídica.

Como se observa, el numeral $3^{\circ}$ del art. 19 establece una garantía de carácter procesal, cuya configuración es considerada por algunos autores como demasiado formal ${ }^{7}$, posición que compartimos al hacer un análisis en bloque de la disposición. Se aprecia que la igualdad consagrada resulta meramente enunciativa desde el momento que, los principales instrumentos (Corporaciones de Asistencia Judicial y Abogados de Turno) generados por el legislador para la efectiva protección en el ejercicio del derecho de acceso a la justicia (salvoconducto de los demás derechos) de todas las personas, han demostrado ser ineficientes e ineficaces para aquel segmento poblacional más necesitado, por ende más vulnerable (grupo para el que las barreras de acceso a la justicia resultan casi infranqueables). Si esto lo contrastamos con el deber del Estado contenido en el art. $1^{\circ}$ de la CPR, de crear condiciones sociales que posibiliten a todas las personas su realización espiritual y material, junto con asegurar el derecho de las personas a participar con igualdad de oportunidades en la vida nacional, cuesta legitimar ciertos mecanismos establecidos por el legislador para el desarrollo de determinadas garantías, como los que a continuación revisaremos.

Bastante se ha discutido sobre si el art. $19 \mathrm{~N}^{\circ} 3$ inc. $2^{\circ}$ alude exclusivamente a la defensa letrada, o persigue consagrar una asesoría jurídica en sentido lato ${ }^{8}$. Nos hacemos cargo de la discusión, planteando que la asesoría técnica de un abogado es sólo una parte de la amalgama de factores que posibilitan un acceso a la justicia idóneo. Empero, preferimos centrar nuestra atención precisamente en este foco, el de la asistencia letrada, pues en torno a ello es que se suscitan los principales problemas del acceso a la justicia de la población menesterosa en Chile.

Tal como mencionamos al iniciar este trabajo, dos son las principales vías que ha consagrado el legislador para la sustanciación de la garantía de acceso a la justicia referente a la asistencia letrada, cuando no es posible para las personas procurárselo autónomamente por falta de recursos, a saber: Corporación de Asistencia Judicial (en adelante CAJ) y Abogados de Turno (en adelante AT). Son múltiples los problemas que aquejan a ambas instituciones ${ }^{9}$, y las críticas al respecto han sido abundantes, es por ello que aquí sólo nos detendremos en las

\footnotetext{
7 Para un análisis detallado de esta postura ver: CARocCa Perez, Alex. "Las garantías constitucionales del sistema procesal chileno", en Ius et Praxis, Derecho en la Región, (2), 1997, p.149.

${ }^{8}$ Sobre una visión más amplia de la garantía de defensa jurídica ver: CAROCCA PEREZ, Alex. op. cit. (n. 7), p. 165. Y para un acercamiento a la postura doctrinal mayoritaria ver: Verdugo, Mario, Pfeffer, Emilio y Nogueira, Humberto. Derecho Constitucional, $2^{a}$ ed. actualizada, Santiago, Chile, Editorial Jurídica de Chile, 1994, pp. 219-220.

${ }^{9}$ Para una mejor apreciación de la configuración legal de estas instituciones y sus dificultades, ver: BALMACEDA J., Nicolás. op. cit., (n. 3), pp. 721-733.
} 
principales dificultades que enfrentan ambos mecanismos de defensa jurídica, sobre todo en aquellas que presentan problemas de armonía constitucional con otros derechos fundamentales.

CAJ es un servicio público, cuyo principal objetivo es dar cumplimiento, por mandato constitucional y respectiva configuración legal, a la garantía de asesoramiento y defensa jurídica a quien no pueda procurárselo a si mismo, principalmente por falta de recursos, de ahí que los servicios que preste sean de carácter gratuito. Pero esta no es su única función, las CAJ son además el lugar físico en el cual realizan su práctica profesional quienes deseen optar al título de Abogado, por tanto esta institución debe otorgar los medios necesarios para que ambas actividades se lleven a cabo. Ambas funciones debieran cumplirse con la mayor eficiencia y eficacia posibles, por los bienes jurídicos que están en juego: 1) acceso a la justicia para los más necesitados a fin de que puedan ejercitar sus derechos con plena igualdad y seguridad jurídica; 2) adecuada formación práctica que deben recibir quienes se desempeñarán como los principales defensores y ejecutores de lo primero, los abogados. De hecho, esta relación dialéctica es casi inherente a la lógica del funcionamiento de las CAJ, ya que su principal mano de obra para atender las necesidades jurídicas y judiciales de la población menesterosa, consiste en egresados de la carrera de derecho, los practicantes, quienes bajo la supervisión de abogados contratado por las CAJ, efectúan patrocinios y orientan a los recurrentes, entre otras funciones. Es sabida y compartida la idea de que aprender haciendo es una modalidad de enseñanza-aprendizaje sumamente relevante, toda vez que los problemas teóricos se transforman en problemas reales, y es necesario aplicar los conocimientos adquiridos y combinar esto con habilidades como creatividad, capacidad de gestión, capacidad de negociación etc.

Sin embargo, aprender haciendo no puede trasformarse en contigo aprendo, pues quienes acuden a las CAJ son personas que adolecen de algo más que recursos económicos, y que no tienen otra vía para defenderse de o frente al aparato jurisdiccional. De hecho, el contigo aprendo, ha sido uno de los principales problemas que han enfrentado las CAJ, debido a las graves falencias de praxis con que llegan los egresados de Derecho, dado la no estandarizada formación práctica que reciben en las distintas universidades. Cabe señalar, que no podemos pretender que un servicio público, cuya principal finalidad es atender las necesidades de relevancia jurídica de la población menesterosa, se encargue de suplir las falencias del saber hacer, pues esta es una responsabilidad que compete principalmente a las universidades (sin descartar la necesaria autoformación, y la experiencia que se adquiere con la práctica en el ejercicio de la profesión a través del tiempo). Las CAJ deben proporcionar el espacio y los recursos estrictamente imprescindibles, para la realización de las prácticas profesionales, pero no están llamadas a subsanar "errores de mercado". Por otro lado, este servicio público debe enfrentar graves carencias de recursos tanto humanos como económicos. Respecto de lo primero, no todas ellas cuentan con asistentes sociales, o sistemas de filtros idóneos, para hacer llegar sólo las causas de relevancia jurídica a los encargados de darles tratamiento. Más grave aún, es el desigual número de abogados con que cuenta cada consultorio comunal y desde luego lo es también, el número de practicantes. Esto último hay que relacionarlo con la cantidad de causas que debe llevar cada practicante con el respectivo abogado supervisor, las cuales superan con creces el mínimo razonable, imposibilitando un buen desempeño de ellas ( $\sin$ contar con las demás funciones que deben asumir como la redacción de escritos o 
atención de consultas, entre otras). En cuanto a recursos económicos se refiere, deficiencias de infraestructura hacen imposible la recepción de un mayor número de estudiantes en práctica (con lo que se retrasa aún más su proceso de titulación), y desde luego la tramitación de una mayor y mejor cantidad de asuntos de relevancia jurídica. A todo esto, hemos de sumar las precarias condiciones en que se llevan a cabo las prácticas profesionales, en que gastos como locomoción, colación y previsión corren por cuenta de los practicantes, olvidando el Estado que son los egresados, uno de los principales instrumentos a través de los cuales da cumplimiento a su deber de garantizar el acceso a la justicia de la población menesterosa. Sin incentivos de ningún tipo para los practicantes, salvo los de carácter pragmático (ejecutar un trámite que es requisito para la titulación), o aquellos de corte altruista (ejercer pro bono para así contribuir con la justicia social del país por unos meses, aunque sea compelidos a hacerlo), este problema también lo padecen los abogados de las CAJ, cuyas remuneraciones, sobrecarga de trabajo, y condiciones laborales en general, les hacen emigrar con frecuencia al sector privado o hacia otras áreas del servicio público.

Con todo, el desarrollo legislativo de la garantía de acceso a la justicia a través de las CAJ, es completamente coherente con los deberes y obligaciones estatales contenidos en la CPR (en la normativa constitucional ya revisados), pero desde una perspectiva estrictamente teórica. Porque es evidente que los problemas de que adolece esta institución en la realidad, son de tal magnitud, que de no generarse reformas en pos de mejorar el funcionamiento de ella, el medio empleado para la consecución del fin propuesto seguirá siendo uno de los principales obstructores de la realización del mismo. Con ello, igualmente se generaría una situación de inconstitucionalidad de carácter fáctico ya que, parafraseando a Nogueira, una asistencia letrada sin efectividad equivale a indefensión ${ }^{10}$, y esta, a su vez, puede transformarse en denegación de justicia cuando, tal como sucede con las CAJ, es el Estado el responsable de asegurar la asistencia a quienes no pueden procurársela por si solos.

En cuanto a los Abogados de Turno, la situación no es muy distinta a la de las CAJ en materia de resultados prácticos que se generan con su intervención, pues aquí la falta de incentivos y de especialización en determinadas materias que toca atender, son inconvenientes que se repiten. Sin embargo, los problemas de constitucionalidad que se presentan respecto de esta institución son alarmantes, pues ya no sólo se entorpece el acceso a la justicia de los más necesitados, por las cuestiones de carácter fáctico ya señaladas, sino que además, se estarían conculcando derechos fundamentales del colectivo afectado por la carga, los abogados. El art. $19 \mathrm{~N}^{\circ} 20$ inc. $1^{\circ}$ establece "la igual repartición de los tributos... y la igual repartición de las demás cargas públicas". Es evidente que el sistema de turnos que deben soportar los abogados, es una carga pública cuyo otorgamiento de manos del legislador adolece de vicio de constitucionalidad por contravenir esta disposición. Ningún otro grupo profesional debe soportar carga semejante, pese a la vital labor social que desempeñan algunos sectores profesionales, y que bien podrían ser objeto de una carga como ésta si el criterio que se ha escogido para gravar a un sector, ha sido el bien jurídico involucrado y la idoneidad del

\footnotetext{
${ }^{10}$ Nogueira, Humberto. La constitucionalización del proceso: el acceso a la jurisdicción, tutela judicial efectiva o debido proceso. En: FERRADA B., Juan Carlos (coordinador). La constitucionalización del derecho chileno. Santiago, Chile, Editorial Jurídica de Chile, 2003, p. 183.
} 
colectivo gravado para protegerlo ${ }^{11}$. Por otro lado, dentro del mismo art. 19, en su numeral 16, el constituyente asegura "la libertad de trabajo y su protección". Este derecho fundamental consagra entre otras cosas, la libertad de que debe gozar toda persona, sin distinción, para poder elegir el trabajo a desempeñar, y que este, además, debe contar con una justa retribución. Desde luego que la razón para gravar a un sector profesional no puede basarse exclusivamente en la idoneidad de su formación, ya que algo así degeneraría en discriminación si no se grava al mismo tiempo al universo de profesionales por su idoneidad en sus respectivas áreas. Por tanto una discriminación en este sentido no es justificable, ni lícita. Este derecho fundamental, se encuentra además blindado al estar consagrado en el Pacto Internacional de Derechos Económicos, Sociales y Culturales, vigente en Chile desde 1989. En su art. $6^{\circ} \mathrm{N}^{\circ} 1$, se establece la necesidad que el Estado reconozca el derecho a trabajar de toda persona, haciendo hincapié en que debe tratarse de un trabajo libremente escogido o aceptado. Si bien la disposición en cuestión apela a la generación de fuentes de empleo para la población, y a la posibilidad cierta de que cada persona pueda ganarse la vida, situación que en efecto alcanza a los abogados, no es menos cierto que la imposición de realizar turnos obligatorios son restricciones, y las sanciones por su incumplimiento (suspensión hasta por 6 meses del ejercicio de la profesión) son privaciones de este derecho fundamental de igual modo. También constituye una infracción grave a la disposición constitucional, y también de carácter internacional (art. $7^{\circ}$ letra i), no otorgar una justa remuneración por la realización de este trabajo, pues ningún otro sector profesional debe soportar sistemas de turnos en que trabaje gratuitamente, cuestión que en definitiva configura verdaderamente la carga ${ }^{12}$. Esta no sería la única normativa de carácter internacional que se estaría trasgrediendo, pues también lo ha sido la "Declaración de la OIT relativa a los principios y derechos fundamentales en el trabajo, la cual en el $\mathrm{N}^{0} 2$ letra b, establece la abolición del trabajo forzoso u obligatorio"13.

Con todo lo dicho, sólo resta sumarnos a la opinión dominante que plantea la inconstitucionalidad e ilegalidad de esta institución, pues carece de fundamento jurídico que en la actualidad la haga sostenible y sustentable en el tiempo, siendo esto último lo más grave, ya que se trataría de un violación sistemática y permanente de derechos fundamentales para con un colectivo específico, los abogados, quienes sin perjuicio de sus propensiones altruistas y sociales, no pueden ni deben ser compelidos a trabajar de manera gratuita, con independencia de lo loable que resulte el fin que se persigue con esta coerción.

Para asegurar el acceso a la justicia de los más necesitados, no cabe alzar el estandarte maquiavélico de que el fin justifica los medios, pues aquí el medio resulta insostenible constitucional y fácticamente. Difícil resultará entonces para lo abogados que se vean compelidos a realizar turnos, llevar buenamente las causas que reciba por este conducto, debido a la carga profesional que ya posee en el ejercicio libre de su profesión, y porque

\footnotetext{
${ }^{11}$ Interesante resulta reflexionar sobre la analogía propuesta en torno a esta idea, por BALMACEDA J., Nicolás. op. cit. (n. 3), pp. 729-730.

12 Para un mayor abundamiento al respecto, y la posibilidad de conocer nuevos alcances de la problemática, a propósito de la designación de abogados de turno en sede Tribunales de Familia, ver: Consejo General Colegio de Abogados de Chile. Situación de la institución abogado de turno. [En línea]. Santiago, 2006. <http://www.colegioabogados.cl/htm/abog_turno_290606.htm>. [Citado 23 de Julio de 2007].

13 OIT. Declaración de la OIT relativa a los principios y derechos fundamentales en el trabajo. [En línea]: $<$ http://www.ilo.org/dyn/declaris/DECLARATIONWEB.static_jump?Var_Language=SP\&var_pagename=DECLARATION TEXT>. [Citado 22 de Julio de 2007].
} 
además debe asumir personalmente gastos y costos de llevar adelante las causas que se le asignen que incluso pueden durar años, sin ser menor el hecho de que la materia de la causa puede no ser su especialidad, lo que entorpece aún más su desempeño.

\section{Normativa internacional}

Habiendo revisado a grandes rasgos el sistema de acceso a la justicia en Chile y sus principales dificultades, cabe señalar algunas conclusiones preliminares. Primero, que la garantía de acceso a la justicia para la población menesterosa, es el resultado de la concepción formal de igualdad que ha asumido y consagrado el constituyente. Segundo, que el desarrollo legislativo para operativizar la garantía de acceso, no estaría condiciéndose con disposiciones constitucionales fundamentales como son los deberes del Estado, que vinculan a toda persona y a todo órgano estatal según lo expresa el Art. $6^{\circ}$ inc. $2^{\circ}$ de la CPR, y principalmente en este caso al legislador.

Y si los mecanismos creados por el legislador para asegurar el ejercicio del derecho de acceso a la justicia de la población menesterosa, no resultan armoniosos con los principios fundamentales que informan nuestra Constitución, a continuación veremos que esta situación de discordancia se traslada a la sede internacional.

Podría pensarse que asumiendo el prisma teórico del bloque de constitucionalidad, estaríamos a salvo de las mezquindades que aquejan a nuestra garantía de acceso a la justicia. Al ser directamente aplicable el corpus normativo internacional sobre derechos humanos (ratificado y vigente), al que nuestro Estado está obligado pues, vía artículo $5^{\circ}$ inc. $2^{\circ}$ de la $\mathrm{CPR}$ es parte integrante de nuestro ordenamiento jurídico, puede presumirse que se encontraría reforzada la protección de los derechos fundamentales consagrados en nuestra CPR, toda vez que habiendo derechos humanos en juego, debiera preferirse aquella norma (interna o internacional) que mejor garantice el derecho en cuestión. Asimismo, cada vez que se intente configurar un sistema para la ejecución de alguna garantía constitutiva de derecho humano, no puede obviarse el derecho internacional correspondiente. Todo esto, en efecto, debiera ser así, pero en Chile la realidad es otra. Se podría creer que con tener un sistema de acceso a la justicia contenido en algunas leyes sueltas, es suficiente para dar cumplimiento a la obligación internacional, pero la norma internacional exige a los Estados obligados algo más que garantías de papel, como a continuación veremos.

Son directamente aplicables, la normativa contenida en la Convención Americana sobre Derechos Humanos (en adelante $\mathrm{CADH}$ ) y la consagrada en el Pacto Internacional de Derechos Civiles y Políticos de Naciones Unidas (en adelante PIDCP), en lo concerniente al respeto de los derechos humanos y a la igual protección que la ley debe otorgar a las personas en el ejercicio de sus derechos, lo cual se lleva a cabo en primera instancia al asegurar, también de modo igualitario, el acceso a la justicia (puesta en movimiento del aparato jurisdiccional).

Es evidente que las garantías de carácter procesal consagradas en estos cuerpos normativos, se encuentran interrelacionadas influyéndose mutuamente, por ello es casi una perogrullada concluir que para que haya una igual protección en el ejercicio de los derechos de las personas, éstas deben contar con la posibilidad real y efectiva de ejercerlos, lo cual se logra 
con un adecuado sistema de acceso a la justicia. Hemos revisado sucintamente las principales barreras a las que se enfrentan los individuos al intentar acceder a la justicia, y una de ellas alude a la asistencia y defensa proporcionadas por un abogado, debido a su alto costo. Resulta evidente la necesidad de contar con asistencia letrada o técnica al momento de enfrentarse al aparato jurisdiccional, no sólo por su complejidad sino sobre todo, considerando las falencias educacionales, sociales y culturales que presentan algunos segmentos de nuestra sociedad. Tanto la CADH en su artículo $8^{\circ} \mathrm{N}^{\circ} 1$ letra e, como el PIDCP en su artículo $14 \mathrm{~N}^{\circ} 3$ letra d, establecen el derecho de toda persona a ser asistido por un defensor de su elección, y en caso de no poder procurárselo, deberá el Estado proporcionárselo en la forma que la ley interna de cada país disponga. Finalmente, ambos catálogos internacionales $\left(\mathrm{CADH}\right.$, art. $2^{\circ}$; PIDCP art. $2^{\circ} \mathrm{N}^{\mathrm{o}} 2$ ), establecen que los Estados en que no existan o no se encuentren operativas las disposiciones imprescindibles para hacer efectivos los derechos que consagra cada pacto, se comprometen (al ratificar el documento) a adoptar las disposiciones legislativas o de otra índole que sean necesarias para dar cumplimiento a las obligaciones internacionales contraídas ${ }^{14}$.

Analizando este conjunto normativo, podemos apreciar que el aporte más significativo del Derecho Internacional de Derechos Humanos en esta materia, ha sido la fijación de estándares de resultado. Esto implica que, en materia de garantías constitucionales no bastan las enunciaciones formales y meramente simbólicas. Lo que se exige es que estas garantías se materialicen y efectivamente permitan la realización del bien jurídico que consagran. En palabras simples, la normativa internacional le exige resultados a los discursos de buenas intenciones; exige que se ejecuten las políticas gubernamentales necesarias para el real, eficaz y suficiente ejercicio de los derechos fundamentales que nuestra carta fundamental consagra, porque de nada sirven las garantías de papel.

\section{Conclusiones}

En consecuencia, podemos constatar con todo lo dicho que, lamentablemente, es cierto que existe aquella disonancia o incongruencia que mencionamos al principio, entre la exigencia de estándares de resultados (efectiva consecución de fines) en la materialización de las garantías de derechos humanos que establece la norma internacional a la que se encuentra obligado nuestro país, y el potencial real de eficacia de las normas chilenas para materializar la garantía de acceso a la justicia de la población en su conjunto, pues respecto de la porción menesterosa no se estarían proporcionando los medios adecuados para su correcta asesoría y defensa letrada. En el entendido de que la asistencia o defensa de un profesional del área es condición sine qua non para una verdadera igualdad de armas. Esta equidad es fundamental para un verdadero, eficiente y eficaz acceso a la justicia, por tanto concluimos que en Chile tal acceso no es igualitario y que esta situación es responsabilidad del Estado. Dicha responsabilidad deviene del hecho de estar obligado a asegurar la protección igualitaria en el ejercicio de los derechos a todas las personas, y esto no se estaría logrando respecto del sector más vulnerable de la población. Es así porque el principal derecho que permite a las personas ejercitar todos

\footnotetext{
${ }^{14}$ Ibid, con artículos respectivos.
} 
los demás, el derecho de acceso a la justicia, se ha visto conculcado para la población menesterosa, precisamente por los medios deficientes que ha generado el legislador para otorgar asesoría y defensa jurídica a este sector.

Esta situación es desde luego factible de mejorarse, por tanto urge reformar el actual sistema de acceso a la justicia en Chile, pues a causa del mismo es que se está produciendo una violación permanente de derechos fundamentales. Abolir los turnos de abogados es una tarea imprescindible para solucionar la situación de vulneración de los derechos fundamentales relacionados con esta institución. Y dentro de las alternativas para generar un sistema de acceso a la justicia de la población menesterosa, que resulte efectivo y suficiente, es menester mejorar las condiciones y situación de las CAJ, robusteciéndolas en todos aquellos ámbitos en que adolece de las dificultades ya mencionadas. Además, existiendo un sistema de acceso a la justicia eficiente y real, donde se involucren servicios públicos eficaces, instituciones como los abogados de turno serían innecesarias.

Por otra parte, el art. $5^{\circ}$ inc. $2^{\circ}$ de la CPR nos permite contar hoy, con un reenvío al sistema internacional de derechos humanos, con lo cual poseemos un bloque de constitucionalidad lo suficientemente integral como para buscar las vías de solución más armónicas con: los principios informadores de nuestra carta fundamental (respecto de los deberes de protección del Estado para con las personas), el catálogo de derechos fundamentales de la CPR y desde luego el corpus normativo internacional sobre Derechos Humanos. Porque en efecto, la norma internacional refuerza el catálogo de derechos humanos de la CPR. Sin embargo, esto de nada sirve si las garantías allí contenidas carecen de eficacia y, por otro lado, el Estado de Chile no está dispuesto a asumir los estándares de resultados exigidos por la comunidad internacional. Entonces, el incumplimiento de la normativa internacional se daría en la realidad, y es precisamente ésta (la eficacia de la norma) lo que le interesa al derecho internacional sobre Derechos Humanos.

Demás está decir que gran parte de la responsabilidad en este problema recae en el legislador, pues es éste quien está llamado a desarrollar los derechos fundamentales para dar vida a las directrices constitucionales. Sin embargo, mediante tal ejercicio no puede en caso alguno y aun a pretexto de la realización de fines honorables e imprescindibles para la inmanencia de la armonía social y la fe en el sistema jurídico, conculcar otros derechos fundamentales, y menos de manera tan grotesca como hemos podido apreciar en el caso de los abogados de turno.

Por otro lado, es evidente que los derechos humanos son límite al poder político, pero también se limitan entre sí, y desde luego que frente a un caso concreto, el ejercicio de ponderación que hagamos puede arrojarnos que un derecho prepondera por sobre otro, pero sólo, para ése caso en específico. Pero, pretender un ejercicio de ponderación generalizado en pos de estructurar nuestro catálogo de derechos humanos jerárquicamente, ordenando de mayor a menor relevancia los bienes jurídicos contenidos en ellos, no haría sino generar dificultades en su igual protección. Compartimos la idea de Martínez-Pujalte de que "no existe jerarquía alguna entre los derechos humanos, pues todos constituyen... la expresión de bienes de importancia básica y radical para las personas humanas, sin que quepa señalar con carácter 
general cuáles tienen una importancia más radical y básica"15. Queda claro, entonces, que no hay derechos privilegiados (en teoría), por ende, es evidente que para asegurar un derecho, el legislador no está autorizado para conculcar otro derecho, al punto de afectar su contenido esencial y restarle toda operatividad práctica (como es el caso del acceso a la justicia en su manifestación de asistencia letrada $\mathrm{v} / \mathrm{s}$ los derechos fundamentales del colectivo abogados de turno). Menos puede el legislador sostener de forma indefinida tal situación, pues esto implicaría como ya señalábamos una violación sistemática y prolongada sin justificación sostenible, de derechos humanos por parte del Estado chileno.

Aceptamos que los derechos humanos no son absolutos, pero su limitación recíproca debe darse del modo más armonioso posible, conforme se estructura y funciona cada sociedad y cada realidad jurídica. Así la limitación que se produzca entre los derechos de nuestro catálogo, será más que una restricción, una acomodación conforme a las necesidades del contexto histórico. Tenemos pleno convencimiento, de que esta acomodación entre los derechos fundamentales, requiere para que opere el sistema adecuadamente, de un ente que oriente y promueva correctamente su configuración acorde a las políticas que surjan para satisfacer las necesidades de la población. Pero una cosa es clara, la labor de esta entidad por muy loables que sean sus intenciones, no puede degenerar en un legislador ineficiente, miope y reticente a actualizarse, que no respete el contenido mínimo que da sentido a un derecho fundamental (derechos conculcados a las personas que participan de las instituciones de acceso a la justicia), o que pretenda asegurar un derecho y hacerlo operativo a través de mecanismos tan ineficientes que terminen entorpeciendo su adecuada realización (garantía de acceso a la justicia en relación con las instituciones propuestas por el legislador para su ejecución). Nogueira resulta esclarecedor a este respecto, afirmando que "al haber un derecho a exigir la tutela judicial efectiva de los derechos ante los órganos competentes, constituye su obstaculización una situación de denegación de justicia, de la cual es responsable, en última instancia, el Estado de Chile, ante los organismos internacionales protectores de los derechos"16.

Hemos de recalcar, que se puede incumplir obligaciones contraídas vía omisión, cuando lo que requiere la norma es una acción positiva de parte del contratante. En lo que respecta al acceso a la justicia en Chile, el incumplimiento de la normativa internacional, se ha visto precedido por configuraciones legales que pretenden dar cumplimiento a las garantías de determinados derechos humanos, sin tomar pleno conocimiento de lo que ello implica, y de cuál es el sistema más adecuado y más completo, que nos permita asegurar de mejor manera el otorgamiento de herramientas de acceso a la justicia. En palabras simples, se ha pretendido dar cumplimiento a la normativa internacional sólo formalmente, nunca de manera sustantiva. Esto último, la miopía legislativa es producto de: a) una deficiente técnica legislativa absolutamente factible de corregirse; b) la falta de voluntad casi patológica para legislar y reformar ciertos temas, sobre todo cuando de contenidos sociales se trata, levemente más difícil de corregir.

\footnotetext{
15 Martinez-Pujalte, Antonio-Luis. La garantía del contenido esencial de los derechos fundamentales. Madrid, España, Centro de Estudios Constitucionales, 1997, p. 129.

${ }^{16}$ Nogueira A., Humberto. op. cit. (n. 10), p. 173
} 
Si internamente el Estado de Chile es propenso a garantizar simbólicamente, ya sea con o sin intención, ciertos derechos, en sede internacional no puede darse e2se lujo, por dos razones. Primero, porque estaría trasgrediendo su propia Carta Fundamental, al hacer caso omiso de la remisión expresa que hace la CPR en su art. $5^{\circ}$ inc. $2^{\circ}$ a la normativa internacional de Derechos Humanos (derechos que en palabras del propio constituyente son anteriores al Estado), y con ello incumpliendo además su deber de respetar la supremacía constitucional, con lo cual se genera una grave afectación a uno de los principios fundamentales y pilar que sostiene todo ordenamiento jurídico, la seguridad jurídica. Segundo, un Estado que se autodenomina democrático y de derecho y que proyecta una imagen de estabilidad a la comunidad internacional, no debe olvidar que estas cualidades (la democracia, la supremacía del derecho y la estabilidad de sus instituciones), se sustentan en una idea contractualista por todos conocida: el Estado encuentra su legitimidad en la soberanía popular que lo erige. Por tanto no puede desoír a sus nacionales cuando le reclaman que respete sus derechos fundamentales, pues dejaría de ser Estado Democrático. Abandonaría su calidad de Estado de Derecho al no respetar su norma fundamental, y temblarían los cimientos de la estabilidad y la paz social, si aquel instrumento otorgado a las personas para el efectivo ejercicio de sus derecho y la posibilidad de hacerlos exigibles, se trasforma en una herramienta tan estéril, tan simbólica, que comencemos a recurrir por necesidad a la autotutela.

\section{REFERENCIAS BIBLIOGRAFICAS.}

BalmaCeda Jimeno, Nicolás. "Corporaciones de Asistencia Judicial y abogados de turno: ¿incumplimiento de una garantía constitucional?” en Revista Chilena de Derecho, Pontificia Universidad Católica de Chile, Nº 27(4), 2000.

CAPELleTtT, Mauro y GARTH, Bryant. El acceso a la justicia, La tendencia en el movimiento mundial para hacer efectivos los derechos. México D. F., Fondo de Cultura Económica, 1996.

CArocca Perez, Alex. "Las garantías constitucionales del sistema procesal chileno”, en Ius et Praxis, Derecho en la Región, (2), 1997.

CONSEJO GENERAL COLEGIO DE ABOGADOS DE CHILE. SITUACIÓN DE LA INSTITUCIÓN ABOGADO DE TURNO. <EN LÍNEA>. SANTIAGO, 2006. [CiTADO 23 DE JULIO DE 2007]. DISPONIBLE EN WORLD WIDE WEB: HTTP://WWw.COLEGIOABOGADOS.CL/HTM/ABOG_TURNO_290606.HTM.

MARTineZ-Pujalte, Antonio-Luis. La garantía del contenido esencial de los derechos fundamentales. Madrid, España, Centro de Estudios Constitucionales, 1997. 
NogueIRA, Humberto. La constitucionalización del proceso: el acceso a la jurisdicción, tutela judicial efectiva o debido proceso. En: FERRADA B., Juan Carlos (coordinador). La constitucionalización del derecho chileno. Santiago, Chile, Editorial Jurídica de Chile, 2003.

OIT. Declaración de la OIT relativa a los principios y derechos fundamentales en el trabajo. $<$ En línea $>$. [Citado 22 de Julio de 2007]. Disponible en World Wide Web: http://www.ilo.org/dyn/declaris/DECLARATIONWEB.static_jump?Var_Language=SP\&v ar_pagename $=$ DECLARATIONTEXT.

Verdugo, Mario, Pfeffer, Emilio y Nogueira, Humberto. Derecho Constitucional, $2^{\mathrm{a}}$ ed. actualizada, Santiago, Chile, Editorial Jurídica de Chile, 1994. 